\title{
LIGHTWEIGHT RECONFIGURABLE STRUCTURE SYSTEM (LRSS): RETHINKING TEMPORARY BUILDINGS
}

\author{
SHAOXIONG LI \& KAIHUAI DENG \\ School of Architecture, Southeast University, PR China
}

\begin{abstract}
The concept of temporary buildings may have many forms or definitions in different countries and regions. In China, they are defined as buildings and structures that are simply constructed for temporary use of production and life and are required to be demolished within a specified period of time. Container houses are the most common type in China. They have been widely used in post-disaster recovery, temporary resettlement of industrial workers and low-income groups. It also plays an important role in different historical stages. It is undeniable that they have the advantages of simple construction technology, fast construction speed, integration and high degree of modularization in practical application. However, from the beginning of the Wenchuan earthquake in 2008, as well as the subsequent series of natural disasters, their design and functional defects were exposed. Through the spot investigation and questionnaire survey, this paper summarized these issues. For the reason that, this study attempts to fill this gap by introducing a new lightweight reconfigurable structure system (LRSS). First of all, in order to meet the needs of national conditions, the system is based on new modular design and manufacturing methods, quick to build and construction, but also easy to disassemble and transport. Moreover, the new design breaks through the traditional style of component form and size restrictions, with more human and sustainable features. Finally, through computer simulation and analysis, it is convinced that the new products have better comprehensive performance. Multiple comparison results are sufficient to illustrate the new structural system can meet the demand of people whom at different age even different social stratum, and ultimately achieve a win-win results from both social and environment system.
\end{abstract}

Keywords: lightweight, reconfigurable, structure system, temporary building, modular design, comprehensive performance.

\section{INTRODUCTION}

Containers are the most representative of temporary buildings and their use in China is very common. For a long time, they were widely used as temporary shelters to help victims of natural disasters and industrial workers involved in large-scale construction. In the past decades, a great deal of work has been carried out by relevant domestic research institutes and administrative units. Its purpose is to improve the comfort level and application scope of the container building. And in 2013, the technical specification for modular freight container building was promulgated. Indeed, compared to canvas tents that people can only use during hard times, container houses have unparalleled advantages in every respect. And it seems that for a long period of time, the use of container buildings as a transitional emergency plan is a global trend [1]. However, we cannot help but ask, is the container house really perfect? For this reason, we chose a temporary container house on a construction site in Nanjing as a research object. On-site inspections and tests were conducted on these container houses, and from our review of various official documents and research papers, some representative problems were integrated to be summarized by four keywords: "safety", "comfort", "beautiful" and "suitable" [2]. At the same time, we also grouped these issues into a questionnaire survey to allow actual users of these container houses to score according to their own experience (Fig. 1). Each question was ranked based on the importance of given needs from "not at all important" to "extremely important". Finally, we received 160 copies of the completed questionnaire, 158 of which were valid. 
Temporary Container House User Experience Survey

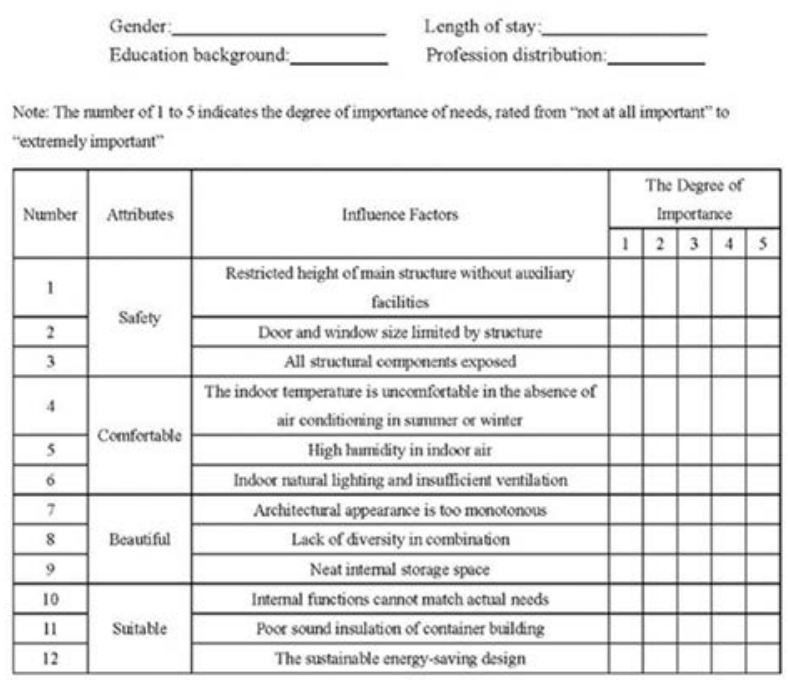

Figure 1: Questionnaire survey.

The vast majority of the respondents lived in a container house for more than three months and less than one year (Fig. 2). The educated information of the respondents is also very consistent with the actual situation, and the occupation distribution is relatively balanced, so it can be said that this statistical survey is extremely representative. After statistically calculating the average score of each sub-item, it can be found that the vast majority of users are most concerned about the comfort of container houses (Fig. 3). In fact, many problems were found in the field investigation. For example, in the autumn of Nanjing, the outdoor temperature at noon is twenty degrees, but when the sun shines directly on the surface of the container, the temperature is close to fifty-six degrees. The final ranking of each individual question also directly corroborates our point of view (Fig. 4). "No air conditioning in summer or winter, the indoor temperature is uncomfortable" is an option that almost everyone feels is in urgent need of improvement, so it's not surprising that it ranks high on the list.

\section{INTRODUCTION}

Lightweight Reconfigurable Structure System (LRSS) (Fig. 5) is a temporary structure based on the concept of industrial product design. Its standard module is a hexagonal cuboid, and its appearance is similar to that of honeycomb structure. This architectural style inspired by the bionics is not to cater to people's visual curiosity, but to make choices based on practical needs. The basic modules of the LRSS can be either independent temporary buildings or they can be combined with each other to form a complex building group. Like the Lego blocks we have played. If we used to be limited by the contradiction between basic modules and diversified combinations, then LRSS is an exception. It has achieved a balance between the two. In addition, different from the traditional architectural design method, it creatively decomposes the building into a skeleton and infill system. Wood and light steel are the two main materials that constitute the LRSS (Fig. 6). The main load-bearing components are made of wood. The connecting parts used to stabilize the entire system are made of light steel. 


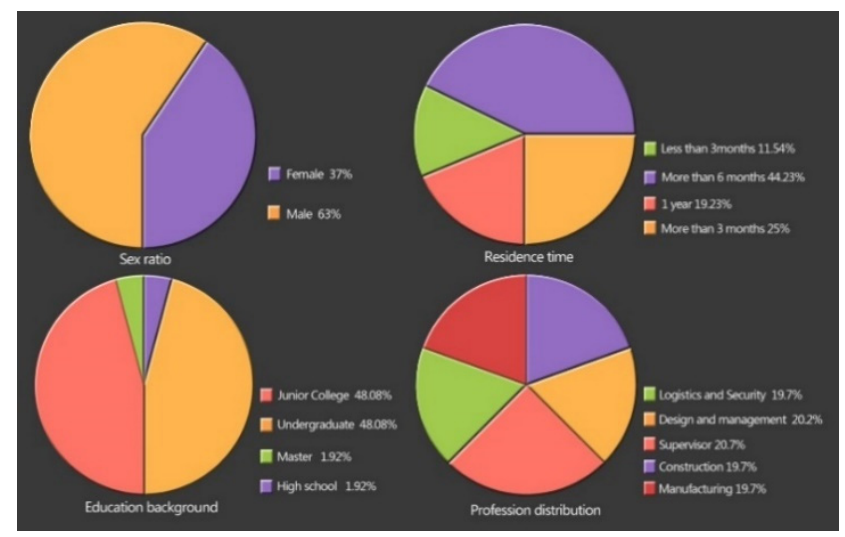

Figure 2: Interviewee information summary.

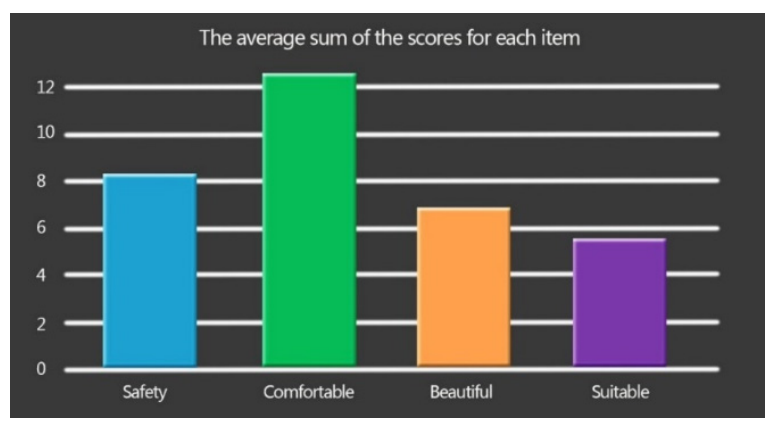

Figure 3: Score statistics of each sub item.

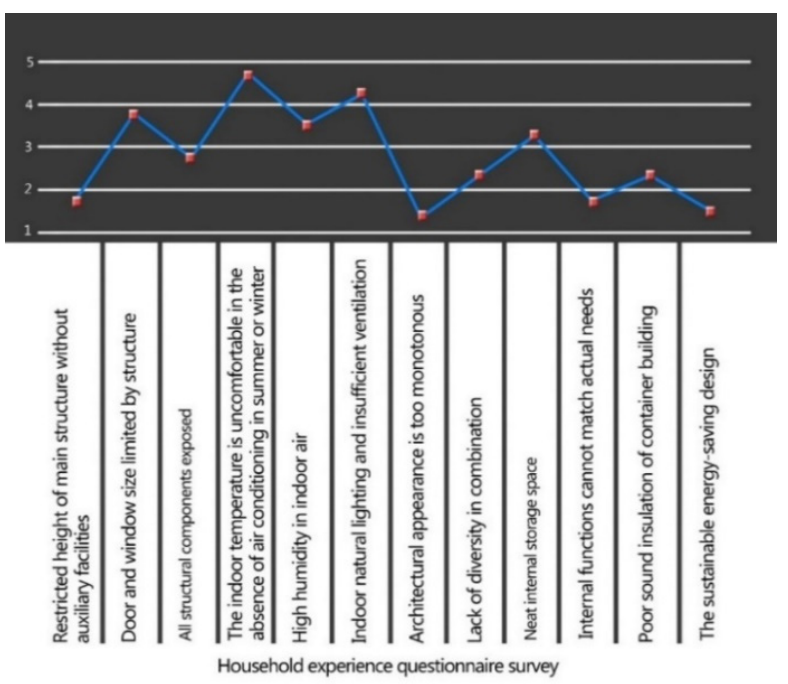

Figure 4: Specific problem score statistics. 


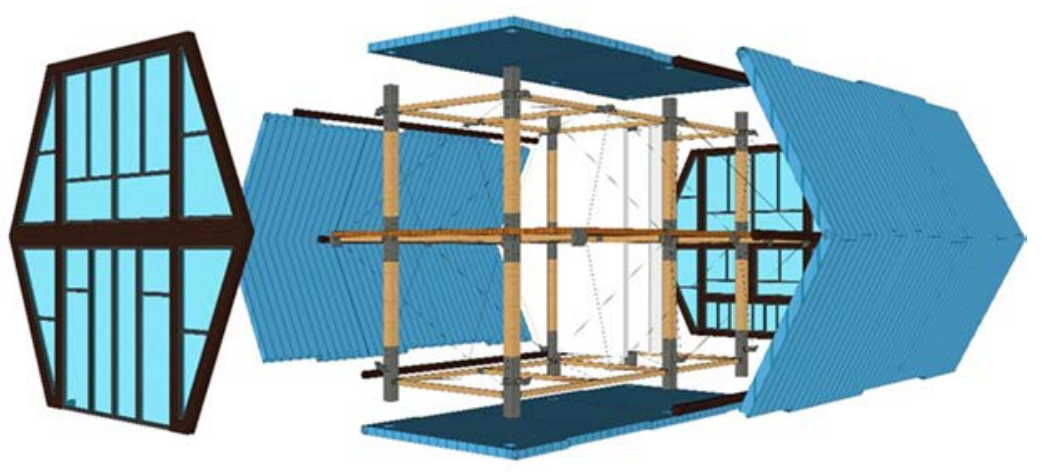

Figure 5: Standard module of LRSS.

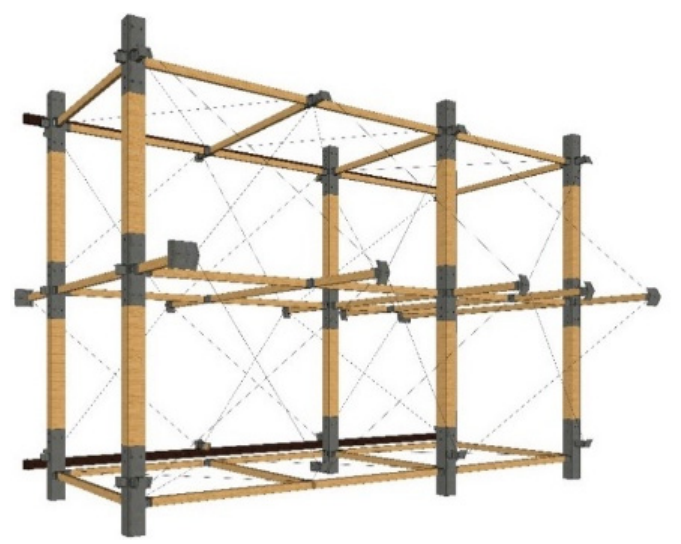

Figure 6: The main structure of LRSS.

Fig. 7 clearly and directly describes the detailed construction method for each connecting node in this new type of temporary building. The two structural columns in the vertical direction are connected by a specially designed light steel component. The connecting part is designed into three segments, the middle section is solid, and the two ends are thin-walled hollow. The column is inserted into the reserved space, and high strength bolts are installed in the reserved holes to achieve the purpose of connecting to each other. At the junction between the outer baffles, there is a connector shaped like an arrow, holding it like a palm. In order to maintain the structural stability to the maximum extent, a long tube is inserted in the horizontal direction at each corner of the hexagon, and the outside baffles are connected in series. Whether it is a roof partition or a middle floor partition, there is a corresponding beam below it as a support member. In the four corners, a specific sheet of metal is used to fix the beams and partitions, while the diagonals are reinforced with slender cables. The splicing method of the entire system draws on the techniques of traditional Chinese wooden architecture. The bolts or mortise-and-tenon joints structure are used among the parts, and the plate are connected by the way of tongue and groove joint. All efforts in this study are aimed at ensuring the firmness and durability of the system as well as maximizing the balance between feasibility and ease of use. 


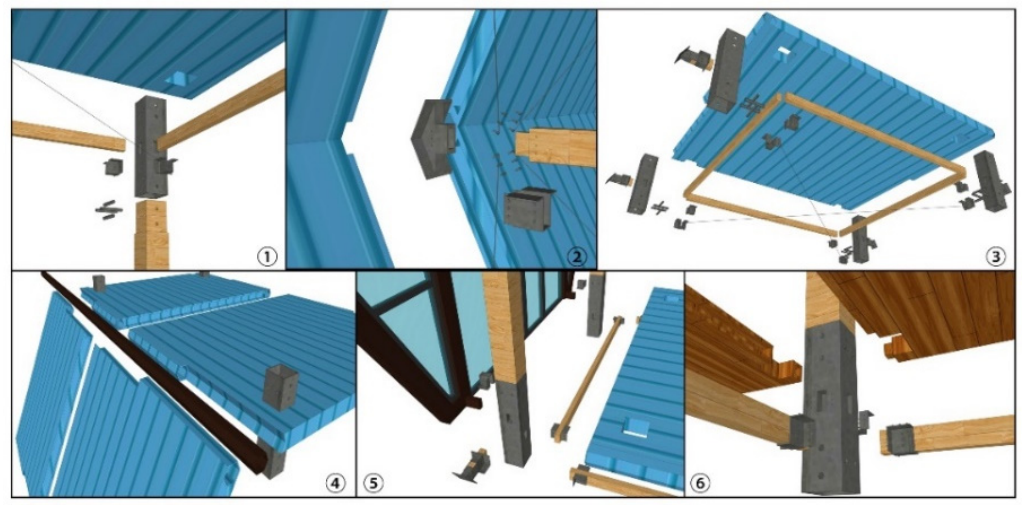

Figure 7: LRSS construction details.

\section{METHODS AND DATA}

This study includes both traditional design strategies, comparative analysis and performance simulation. The foregoing has described a series of shortcomings in the actual application of existing container houses. Based on China's social and economic conditions, this study needs to be more intuitive to explain the feasibility of promoting LRSS as a temporary building. Since it is a new product, it is necessary to meet the actual needs of the people.

\subsection{Net size}

Table 1 shows the outer and inner dimensions of the two most commonly used containers. Due to the fact that numbers can't really make people feel the building space, this study draws the standard layout of two container buildings. As can be seen from Fig. 8, because of size constraints, it is difficult for containers of type ICC to form a fully functional dwelling unit and narrow inner channel affects the real experience of the resident. In addition, no matter which type of container, in such a compact space cannot be arranged reasonable storage space. The vertical section of the LRSS is hexagonal with a net width of $3100 \mathrm{~mm}$ at the bottom edge and a horizontal distance of $6400 \mathrm{~mm}$ between the two furthest corners in the middle and a vertical height of $4800 \mathrm{~mm}$ (Fig. 9). In the direction of the long axis, the bottom layer consists of an $8300 \mathrm{~mm}$ indoor space (intermediate layer is reduced to $6600 \mathrm{~mm}$ ) and an outdoor platform of $3300 \mathrm{~mm}(1800 \mathrm{~mm}$ on the outermost side of the platform is removable).

This design can be seen as the optimization and integration of an IAA container in three dimensions. The aim is to reduce unnecessary walking distance as much as possible without

Table 1: Size of two general types of containers [3].

\begin{tabular}{|c|c|c|c|c|c|c|c|}
\hline \multirow{2}{*}{ Model } & \multicolumn{3}{|c|}{ External size } & \multicolumn{3}{c|}{ Internal size } & \multirow{2}{*}{ Rated quality(kg) } \\
\cline { 2 - 7 } & $\begin{array}{c}\text { Height } \\
(\mathrm{mm})\end{array}$ & $\begin{array}{c}\text { Width } \\
(\mathrm{mm})\end{array}$ & $\begin{array}{c}\text { Length } \\
(\mathrm{mm})\end{array}$ & $\begin{array}{c}\text { Height } \\
(\mathrm{mm})\end{array}$ & $\begin{array}{c}\text { Width } \\
(\mathrm{mm})\end{array}$ & $\begin{array}{c}\text { Length } \\
(\mathrm{mm})\end{array}$ & \\
\hline ICC & 2591 & 2438 & 6058 & 2393 & 2352 & 5898 & 2180 \\
\hline IAA & 2591 & 2438 & 12192 & 2393 & 2352 & 12032 & 3640 \\
\hline
\end{tabular}



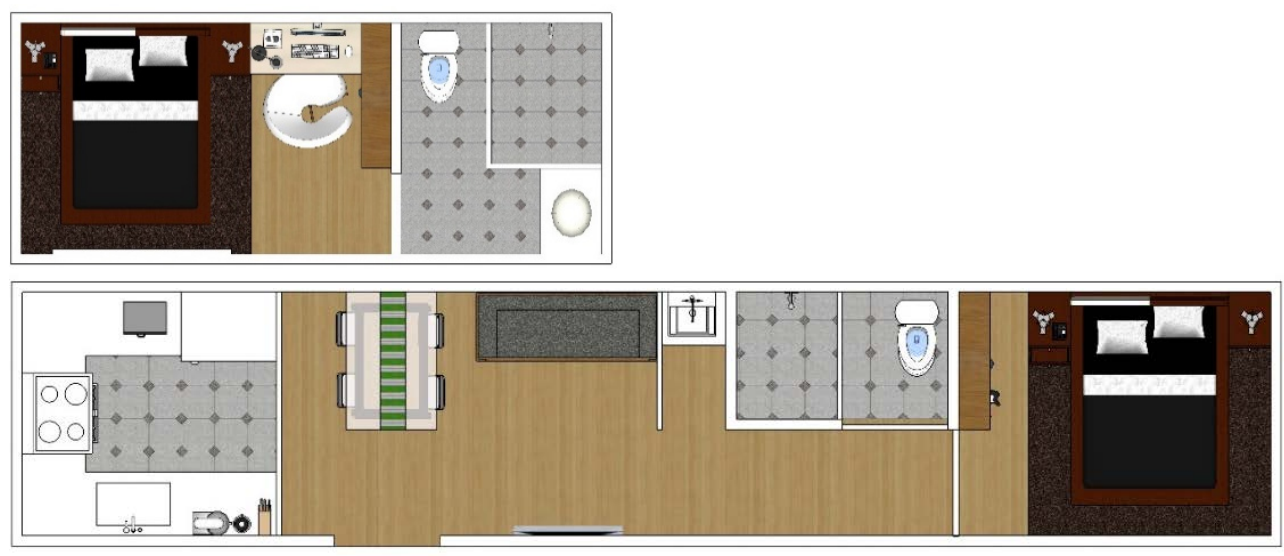

Figure 8: Standard layout of two container buildings.
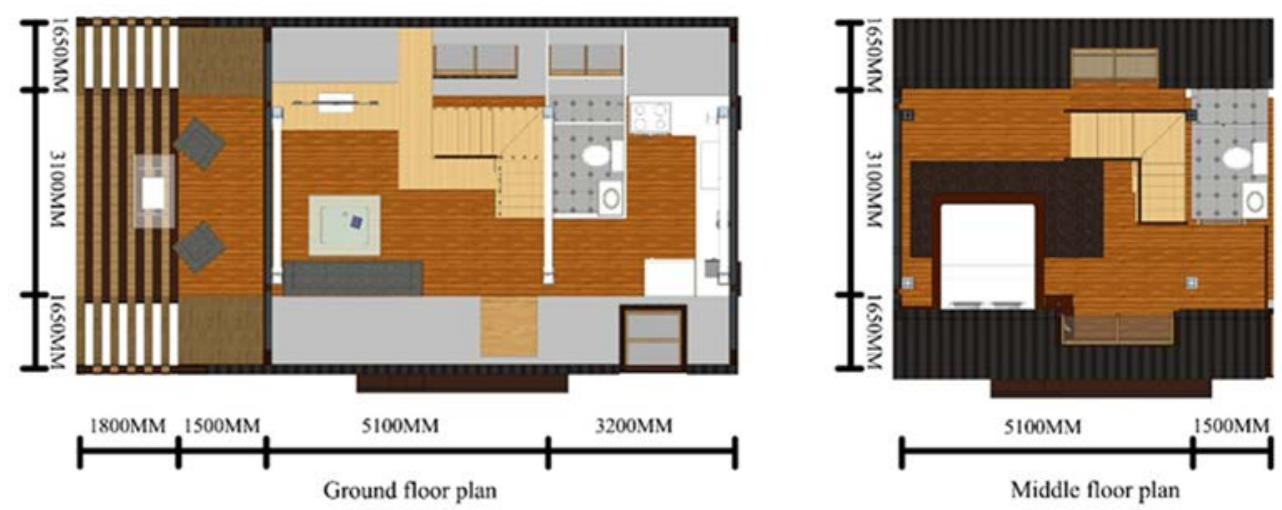

Figure 9: Standard layout of LRSS.

giving up any functional space. In particular, it is possible to avoid the appearance of a narrow corridor connecting all functional spaces, which is very affecting user experience. In addition, a more reasonable functional configuration is achieved when the overall size does not increase significantly. The most significant is that there is an extra terrace for people to relax on the ground floor platform, and a bathroom close to the bedroom (Fig. 10).

\subsection{Comfort degree}

The body sense comfort should be considered as an important index of a kind of building. Unfortunately, When policymakers and investors see low-cost container buildings, everything seems to be less important. In order to get the most intuitive conclusion, this study takes the layout of IAA containers as an example to conduct a computer simulation of internal ventilation. In this experiment, according to the difference of wind direction, we simulated the ventilation in the container house respectively (Figs 11 and 12). 


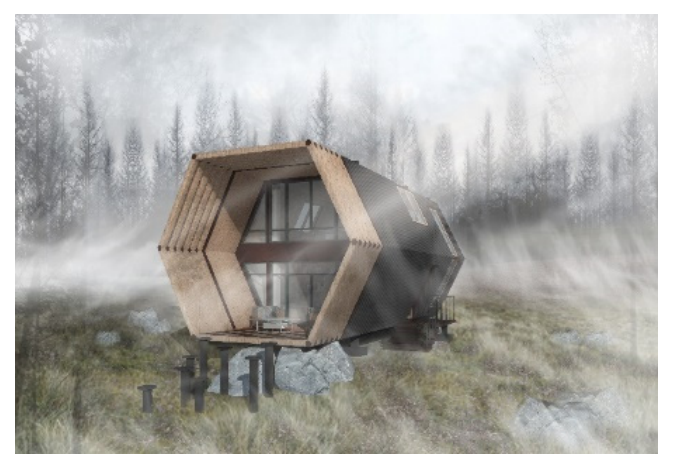

Figure 10: Three-dimension effect graph of LRSS.

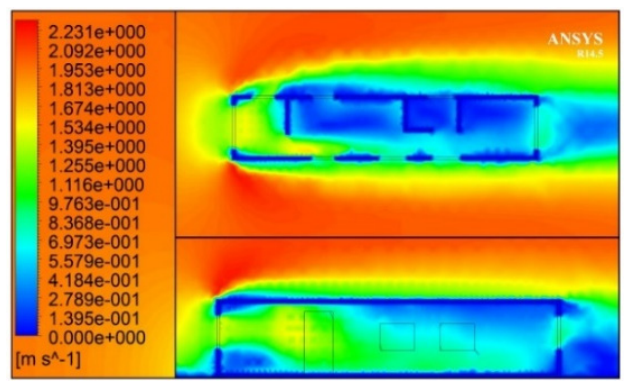

Figure 11: Horizontal ventilation simulation.

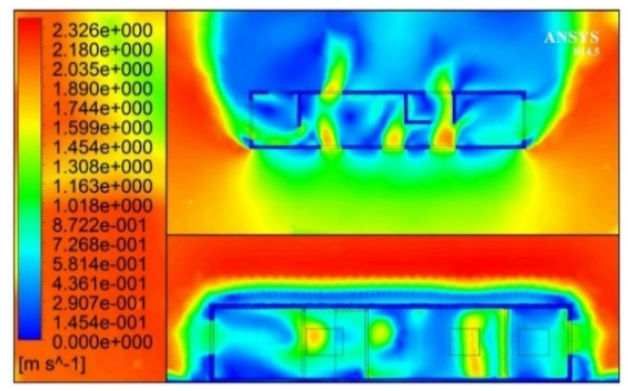

Figure 12: Vertical ventilation simulation.

As shown in Fig. 11, the airflow in the horizontal direction is limited by the size of the container side structure, and the air is easily blocked by the interior wall so that it cannot provide enough fresh air for the room. Therefore, most functional spaces cannot feel comfortable with natural ventilation. Even though the corridor space runs through the room, the air flow also shows significant attenuation as the distance increases. The long side of the container has enough space to enlarge its window-to-wall ratio. So as shown in Fig. 12 the indoor ventilation has improved significantly when the dominant air flow comes from the vertical direction. Especially when there are corresponding windows in the same position on 
both sides, there will be obvious air convection effect. It remains to be said that the so-called "equilibrium" problem we have been emphasizing has not been properly addressed. It can be clearly seen that the ventilation effect in the bedroom and living room still needs to be improved.

Through computer simulation, we can most intuitively see the indoor wind environment of LRSS. And in order to make the simulation results more persuasive, the parameters and boundary conditions set in this simulation are consistent with the previous container simulation. Compared with traditional container houses, the position of windows in the LRSS is more reasonable, so it can be clearly seen from Fig. 13 that there is a significant convective wind effect in the interior of the LRSS. Fig. 14 shows that the air flow entering from the vertical direction can easily penetrate the entire space.

\subsection{Operating energy consumption}

product that meets the needs of the current people, is bound to conform to the characteristics of this era. In order to make the subsequent energy-saving measures and design strategies more detailed and effective, this study separately conducted computer analysis of the energy consumption of the IAA container house and the LRSS. The simulation results of two different types of temporary buildings are derived from a software called EnergyPlus (version

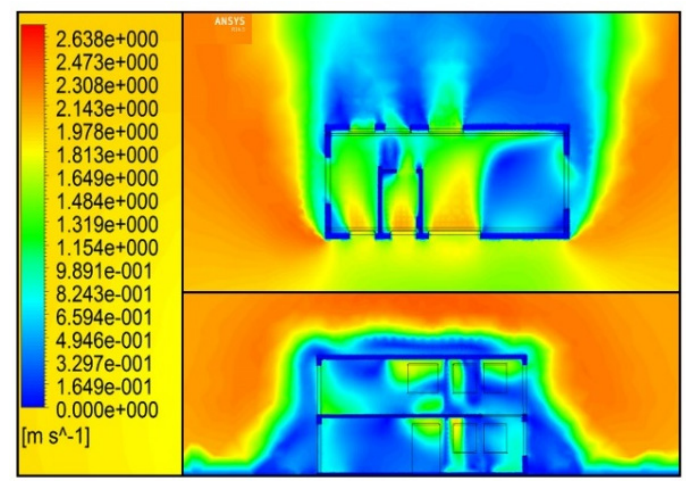

Figure 13: LRSS horizontal ventilation simulation.

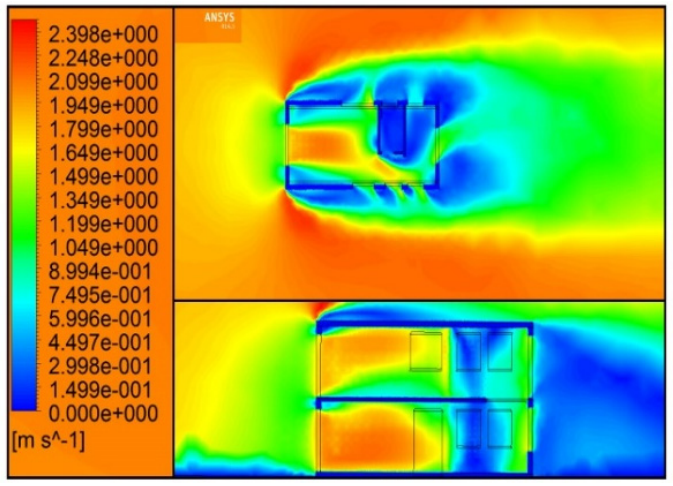

Figure 14: LRSS: vertical ventilation simulation. 
8.8). The two simulation setup has the same external boundary conditions to highlight the difference in thermal performance between different materials. Fig. 15 shows the annual energy consumption results of the two buildings when we set the indoor temperature at 25 degrees centigrade, the same number of residents, the same climate zone, and the same electrical equipment. The results show that in the nearly $2 / 3$ months of the year, the operating energy consumption of LRSS is much lower than that of traditional ones, and the gap between them is significant. The main reason for this situation is that the building materials used in the original system have been overemphasizing lightness and neglecting thermal performance for a long time.

Today, energy saving and environmental protection has become a hot topic. LRSS, as aIn response to this phenomenon, this study combined with the LRSS's own characteristics has innovatively designed the specific structure of the enclosure sheet and matched the corresponding materials. The building envelope of LRSS is constructed in the form of "sandwich". The outermost side of this lightweight composite wallboard consists of two pieces of larch structural plywood. The middle cavity is filled with two pieces of polyurethane foam. Polyurethane foams are connected by GFRP keels and also come with an air gap (Fig. 16). GFRP is a new type of building material. It has excellent material properties

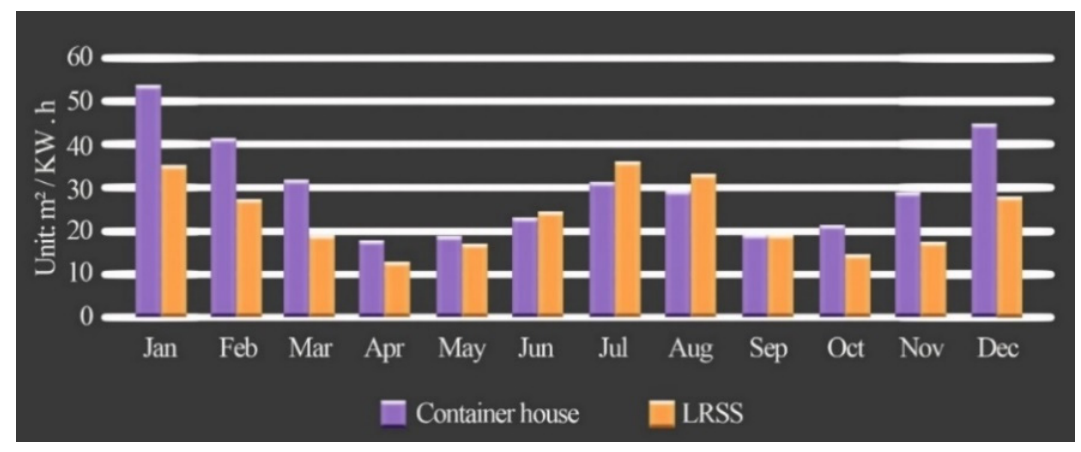

Figure 15: Simulation of operation energy consumption.
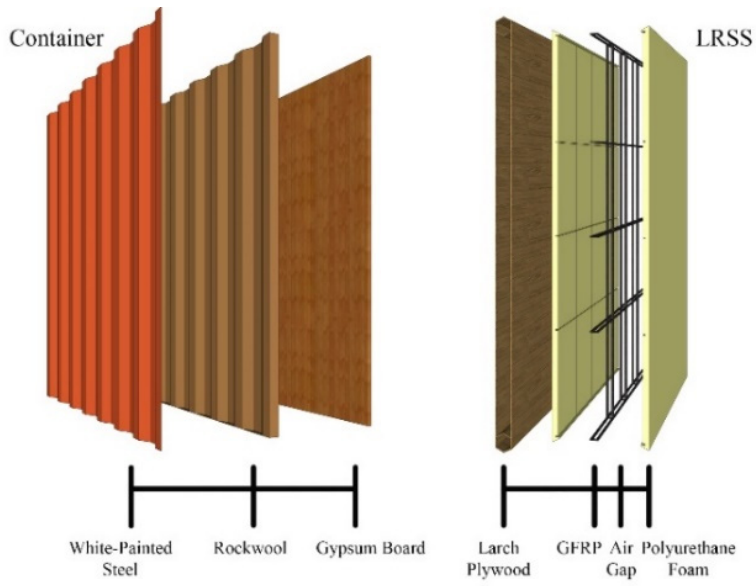

Figure 16: Material composition of envelope. 
such as light weight and strong anti-deformation ability, also provides a variety of options for LRSS modeling and lapping.

As mentioned earlier, the thermal performance of materials affects the overall energy performance of the building. The materials used by LRSS have good physical properties compared with the traditional ones (Table 2). However, it should be noted that LRSS has higher energy consumption in summer. After in-depth analysis, we found that the causes of this consequence are two aspects. First, the two side facades of the LRSS are made of glass, and when the summer comes, there will be a lower thermal insulation performance. Second, overemphasizing the simplicity of the overall design and neglecting the design of effective shading members. All the defects found in this research will be solved in the following "prototype improvement" research.

\subsection{Transport and construction}

As time goes by, the cruel lessons in practical use tell us that there is still a huge gap between expectations and reality. In 2013, School of Architecture of Southeast University participated in the first solar decathlon competition held in China. The Solar Decathlon is an international competition among universities created by the U.S. Department of Energy and related to high-performance residential-related research [8]. Taking into account many factors, they chose to use three IAA containers as the main framework. Because it is necessary to comply with the relevant regulations of China's highway transportation safety regulations, the 12meter-long IAA container consumes a lot of money and time in the transportation process. Furthermore, due to the temporarily dispatched for on-site construction, they are still not completed on time [9]. Not only that, but also based on the preconditions for ensuring the safe use of container houses, relevant regulations have made corresponding restrictions on the side window opening dimensions and building height of the container according to the structural characteristics of the container itself. The staircase in the picture seems to be only a function of vertical traffic, but its larger role is to resist the possible lateral thrust for the main structure as shown in Fig. 17.

At the beginning of its design, LRSS took into account the subsequent transport and construction problems. The core of its design concept is to divide the LRSS into independent functional modules so that the LRSS can be quickly delivered to the destination with only small vehicles. All the parts are custom-manufactured by the factory, and only a few workers and equipment are needed at the site to quickly assemble a fully functional unit. The only

Table 2: Material's physical property parameters [4]-[7].

\begin{tabular}{|c|c|c|c|c|c|}
\hline \multicolumn{2}{|c|}{$\begin{array}{c}\text { Material thermal conductivity of IAA } \\
\text { type container }\end{array}$} & \multicolumn{3}{|c|}{$\begin{array}{c}\text { Material thermal conductivity of light } \\
\text { reconfigurable structure system }\end{array}$} \\
\hline Material & Thickness & $\begin{array}{c}\text { Thermal } \\
\text { conductivity }\end{array}$ & Material & Thickness & $\begin{array}{c}\text { Thermal } \\
\text { conductivity }\end{array}$ \\
\hline Steel & $2 \mathrm{~mm}$ & $58.2(\mathrm{~W} / \mathrm{mK})$ & $\begin{array}{c}\text { Larch } \\
\text { plywood }\end{array}$ & $10 \mathrm{~mm}$ & $0.16(\mathrm{~W} / \mathrm{mK})$ \\
\hline $\begin{array}{c}\text { Rock } \\
\text { wool }\end{array}$ & $8 \mathrm{~mm}$ & $0.045(\mathrm{~W} / \mathrm{mK})$ & GFRP & $10 \mathrm{~mm}$ & $0.35(\mathrm{~W} / \mathrm{mK})$ \\
\hline $\begin{array}{c}\text { Gypsum } \\
\text { board }\end{array}$ & $10 \mathrm{~mm}$ & $0.33(\mathrm{~W} / \mathrm{mK})$ & Air gap & $10 \mathrm{~mm}$ & $0.023(\mathrm{~W} / \mathrm{mK})$ \\
\cline { 4 - 6 } & & $\begin{array}{c}\text { Polyurethane } \\
\text { foam }\end{array}$ & $40 \mathrm{~mm}$ & $0.033(\mathrm{~W} / \mathrm{mK})$ \\
\hline
\end{tabular}




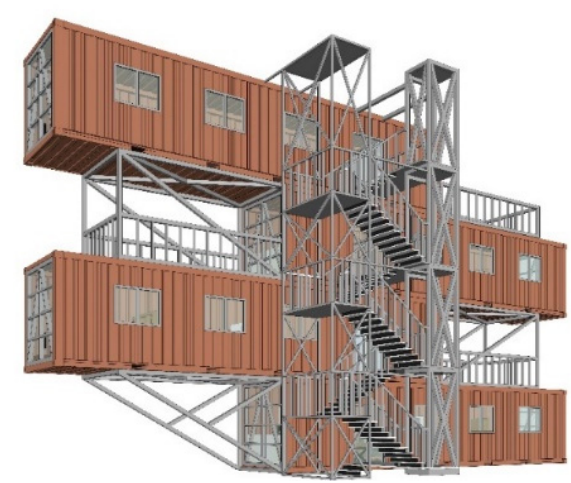

Figure 17: Combination form of container house.

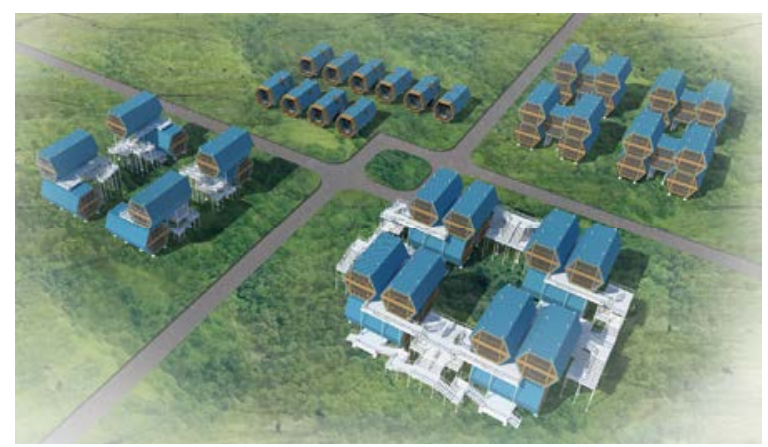

Figure 18: LRSS combination form.

organization principle of functional modules is adaptive adjustment based on different customer needs and different usage environments. As shown in Fig. 18 LRSS fully demonstrates the diversity of its construction form. More specifically, LRSS itself can be used as a structural stress system without the need to build additional support platforms.

\section{RESULTS}

In summary, due to a series of obstacles such as its internal dimensions, thermal comfort, and structural strength, it is difficult for container buildings to adapt to the requirements of people in the new era. The LRSS in this study is a brand-new product with targeted optimization and upgrading. And based on sustainable design principles, each component designed in LRSS has a set number of reusable times. This will greatly reduce the risk of damage to various components and greatly reduce unnecessary waste of resources. Taking into account the growing maturity of solar photovoltaic integrated products in the future, the special shape of LRSS is to leave room for future transformation. So in areas with high solar radiation, LRSS can not only achieve its own net zero-energy operation, but also have a greater chance of providing energy for the municipal grid. Of course, it is undeniable that as a prototype of new products, we find that there is room for improvement. For example, the problem of excessive energy consumption in the summer LRSS mentioned above. In subsequent studies, we will design targeted sunshade components and optimize window wall ratio. 


\section{CONCLUSION}

Based on the above discussion, LRSS as a temporary housing module with the concept of industrial products has its advantages. Its appearance will lead to more extensive and in-depth discussions on temporary housing. People began to realize that temporary buildings are still as comfortable, beautiful and durable as ordinary houses. More importantly, it serves as a new exploration path, providing practical and effective lessons for subsequent research, and ultimately becomes the reference for the state to issue relevant regulations.

\section{ACKNOWLEDGMENTS}

The research presented in this paper was supported by "the Fundamental Research Funds for the Central Universities" and Postgraduate Research and Practice Innovation Program of Jiangsu Province (KYCX17_0109).

\section{REFERENCES}

[1] Perrucci, D.V., Vazquez, B.A. \& Aktas, C.B., Sustainable temporary housing: Global trends and outlook. Procedia Engineering, 145, pp. 327-332, 2016. DOI: 10.1016/ j.proeng.2016.04.082.

[2] Huang, L. \& Long, E., Architecture and planning design strategy of post-disaster temporary settlement with high building density: analysis based on the questionnaire in Dujiangyan after Wenchuan earthquake. Procedia Engineering, 121, pp. 101-106, 2015. DOI: $10.1016 /$ j.proeng.2015.08.1028.

[3] China Steel Construction Society(CSCS), Technical Specification for Modular Freight Container Building, China Planning Press: Beijing, 2013.

[4] Song, Y., Mithraratne, N. \& Zhang, H., Life-time performance of post-disaster temporary housing: A case study in Nanjing. Energy and Buildings, 128, pp. 394-404, 2016. DOI: 10.1016/j.enbuild.2016.07.019.

[5] Wang, X., Fei, B., Zhou, H. \& Ren, H., Steady-state heat transfer performance of domestic light-frame wood wall. Journal of Civil, Architectural and Environmental Engineering, 4, pp. 76-79, 2010.

[6] Bai Y. \& Keller, T., High Temperature Performance of Polymer Composites, WileyVCH Verlag GmbH \& Co: Weinheim, pp. 64-102, 2013.

[7] Zhao, L., Calculation analysis of heat insulation performance of double-skin roof's air layer, HangZhou: ZheJiang University, pp. 22-23, 2008.

[8] King R.J. \& Warner, C., Solar decathlon: energy we can live with. Proceedings of the 3rd World Conference on Photovoltaic Energy Conversion, pp. 2139-2142, 2003.

[9] Peng, C., Huang, L., Liu, J. \& Huang, Y., Energy performance evaluation of a marketable net-zero-energy house: Solark I at Solar Decathlon China 2013. Renewable Energy, 81, pp. 136-149, 2015. 